\title{
THE ROLE OF PUBLIC SPACE TO ACHIEVE URBAN HAPPINESS
}

\author{
M. SEPE \\ IRISS C.N.R.- DiARC University of Naples Federico II, Naples, Italy.
}

\begin{abstract}
Urban happiness can be defined as a concept that gives a positive perception of a place to the people who live in it and which induces them to spend a long time there and/or to opt to live there again with the same experience. While the identification of a happy place is something that is quite achievable, it is more difficult to investigate how to obtain it. The aim of this article is to present the Happy place mapping, which is carried out in the framework of CNR research projects. The Happy place mapping aims at identifying sustainable urban happiness and the factors that make places happy from the users' point of view as well as identifying design interventions to enhance or create it. The method consists of surveys, observations and questionnaires. A series of case studies have been carried out in Europe, the United States and China. These case studies resulted in a Charter of Urban Happiness of 20 principles, which is part of the method. The description of the software that can support the method, still under development, and observation both on the method and software conclude thearticle.

Key words: place identity, public space, sustainable development, urban design, urban happiness.
\end{abstract}

\section{INTRODUCTION}

Senses are part of everyday life and the sensory experiences from having lived in a place allow people to remember the place in a pleasant and distinctive way [1-5]. Through the analysis of places, a more detailed and qualitative interpretation of the city is arrived at. This is not circumscribed to its aesthetic essence, or even to its physical geometry. The functional and symbolic interpretations of the elements of a place are the fundamental factors for understanding its meaning. In addition, "as society changes, so does signification. Meanings attached to the built environment become modified as social values evolve in response to changing patterns of socio-economic organisation and lifestyles" [6].

As Relph [7] asserts, "Perceptive space is a space of action centred on immediate needs and practices, and as such it has a clearly developed structure. (...) This structure can clearly be in no way understood as objective or measurable - rather distances and directions are experienced as qualities of near or far, this way or that, and even when these are made explicit as paths or trails they are known with their special meaning. (...) Perceptive space is also the realm of direct emotional encounters with the spaces of the earth, sea, and sky or with built and created spaces".

Urban studies agree with the fact that, increasingly, the goal of project interventions in an urban space is to alter the experience of that space for its residents. Urban environments are designed to be increasingly distinctive, in trying to create memorable sensory experiences and give happiness to the people who use them. Even people who visit ordinary urban centres can describe, given by the five senses, a series of emotional experiences relevant to those places. And these experiences can be very different from one place to another [8-20]. 
Nowadays, new attention to urban happiness has been given but often in terms of theoretical sense or from an observational point of view [21-25].

Starting from these premises, the aim of this article is to present the Happy place method, carried out in the framework of National Research Council research project.

The definition of urban happiness is strongly interwoven with social, environmental, economic and philosophical studies and, in accordance with the quick transformation of lifestyles, needs and habits, the definition is in the process of continuous change. On the other hand, the definition appears to be similar to that used for defining well-being, quality of life, and, in a certain sense, sustainability. Urban happiness can be defined as a concept that gives a positive perception of a place to the people who live in it and which induces them to spend a long time there and/or to opt to live there again with the same experience.

Starting from these premises, the aim of this article is to present the Happy place mapping, carried out in the framework of CNR research projects. The Happy place mapping aims at identifying sustainable urban happiness and the factors that make places happy from the users' point of view as well as identifying design interventions to enhance or create it. The method consists of surveys, observations and questionnaires. A series of case studies have been carried out in Europe, the United States and China. These case studies resulted in a Charter of Urban Happiness of 20 principles, which is part of the method. The description of the software that can support the method, still under development, and observation both on the method and software conclude the article.

\section{THE METHOD}

The 'Happy place mapping' method consists of five phases [12-13]. The first phase consists in the selection and definition of the study area. It needs to go on the site in question and, through an inspection, decide whether to confirm the delimitation decided beforehand or modify it.

The second phase is characterized by the observation of the characteristics of the place through three surveys concerning activities, perceptions and elements that contribute to the perception of happiness.

In the first survey, it needs to observe the types of people (locals, visitors, professionals) and activities (enjoyment, passing by, work, etc.). These activities are measured from the quantitative point of view, namely observing upto what percentage an activity is present in that place and how it influences liveability.

Similarly, the presence of persons is measured from the quantitative point of view as well. Then it needs to observe the frequency with which the activity is repeated or implemented and with what pace; namely, if that activity is carried out with a rapid, slow or moderate pace.

The second survey consists in the identification of singular visual, auditory, tactile, olfactory and taste perceptions as well as mixed perceptions, such as chaos, serenity, disorder, joy, harmony, disorientation and so on, deriving from the sum of one or more perceptions. Then it needs to observe their quantity expressed in terms of light, medium and high percentage as well as the their quality expressed in terms of being pleasant, non-influential and annoying perceived perception.

The third survey of this phase consists in the observation of the elements that contribute to the sensation of happiness such as constructed and natural elements, transportation modes, equipment and services (furniture, wireless, etc).

Finally, from the data resulting from surveys on this place, a first result on the degree of happiness is obtained,. 
The third phase consists of a questionnaire to the users of the site aimed at identifying factors and elements that make people who live in that place either happy or sad.

Questions may include the following and may be modified in accordance with the characteristics of the place:

- Does the place give you a feeling of happiness or sadness?

- What are the elements that make you happy/sad here?

- What are the facilities that make this place good or bad?

- What kind of activities do you carry out in this place? How often?

- The presence of many or few people improves the pleasantness or unpleasantness of the place?

- What could be done in order to improve this place?

- Which is a happy place that you remember to have lived in, in this city or elsewhere?

- Do you think that the weather conditions might influence the perception of this place?

The fourth phase is that of the analysis of the cartography in order to understand the elements that compose the place in terms of the type of urban fabric, the historical and architectural elements, the natural environment (sea, hills, etc.) and other public spaces in the surrounding area.

The fifth phase involves the construction of the map of happiness with the identification of spaces and features that give the perception of happiness to the people who use that place.

The map will be the result of all the information collected with the different survey operations, analysis and observation.

\section{THE CHARTER OF URBAN HAPPINESS}

The principles for urban happiness in a public space are based on the findings of the case studies carried out using Happy place mapping. As previously mentioned, the Charter is meant to be an open and flexible tool for academics, practitioners and administrators for the creation or enhancement of happy places.

The premise of this Charter is that a happy place is a space that can transmit a feeling of happiness to anyone who uses it.

1. It is important that both the place identity and the intangible characteristics of the site and its surroundings are present in a public space. The identity of a place means - as defined by Kevin Lynch - a set of characteristics that make the place unique and recognizable is given by urban and architectonic elements - namely tangible - and by elements connected to the perceptions. A smell or a view is capable of making us remember a place as well as or more than a square or an architecture and to determine positive emotions in one who looks it. This is a fundamental element for urban happiness. It is further important to make surroundings agreeable as well, and enhance the identity of a place in order to not create a place that is not harmonized with the external parts.

2. It is important to encourage the use of the place by people of different age groups, from children to the elderly and not to have architectural barriers that might discourage people from frequenting that space. The living together of more generations of people constitutes a factor of importance because it provides evidence of the presence of different activities, times and rhythms of diverse use, and the non-existence of architectonic barriers. Indeed, these can constitute obstacles for children, elders and the handicapped. 
The possibilities to carry out activities devoted to all ages provide attraction to the place.

3. A public space should allow different types of functions (games, breaks, walking, etc.). It is also desirable to facilitate gymnastic activities with the presence of small equipment or even a designated space. Activities should be relevant to age groups in order to allow a mix of uses during various periods of the year. The presence of sport activities constitutes a further activity and will make the place more attractive and healthy.

4. The possibility of performing actions that normally are not permitted, such as walking barefoot in the water or in designated public areas, creates a feeling of freedom and joy. A place such as a public space is a place where it is more possible to imagine activities that usually are not carried out in other typologies of places. The presence of materials such as sand, water or any other material that allow actions such as to sit down without shoes offer particular perceptions of freedom and well-being.

5. The composite elements of the space should have an appropriate balance between the elements of nature, landscape and equipment. The environment in the different forms, as those generated by nature and those generated by man (landscape) are important in influencing sensorial activities such as view, touch and taste. A suitable mix of environments and equipment to enjoy these constitute an important factor for the urban happiness of a place.

6. The presence of water in different shapes (e.g. fountains) promotes the vitality of the place. Water in its shapes and sounds - as well as for that which concerns the possibility to create aggregative activities (e.g. paving with water games,..) - constitutes a factor that is important in order to create emotions in a place.

7. The presence of art in its different forms is desirable. Art constitutes a factor that is able to cause emotions favouring a condition of happiness. Furthermore, some art works constitute aggregative elements in itself due to the own potential of dynamism that they possess.

8. The presence of sculptures, games, or other elements and amenities that can bring a smile to a person's face promotes a state of happiness. The typical cases in this sense are the installations and sculpture which to be seen require movements. The possibility to use urban sculpture in its value for socialization, favours the atmosphere of happiness of the place.

9. A public space should have natural lighting during the day and artificial at other times. Artificial light during the day should be avoided. Natural and artificial light constitute an important factor for urban happiness because they can both be associated with different actions and allow a condition of safety. Sun light allows conditions of both physical safety and emotional well-being. Artificial light allows many actions such as walking, biking, taking a break and other actions that cannot be easily carried out during the dark hours.

10. An adequate state of cleanliness and maintenance must be maintained. The management of a public space with suitable maintenance of cleanliness and maintenance of its different areas is necessary to determine the well-being of that place. Bad maintenance offers an image of disuse that can favour nonpositive behaviour.

11. A public space has to give a sense of security and safety to those who walk in it. The possibility of carrying out functions during the day contributes to the creation of a perception of safety because it offers the idea that people can live in the place in a moderate or slow pace. These actvities have to be facilitated with suitable lights - also with artistic function - in order to improve the perception of safety.

12. It is important that noise generated by public transport is either minimized or entirely 
absent. The sound perceptions by an element can constitute of being capable of offering perceptions of happiness, such as in the case of the sound of elements of nature; not only water, but also the vegetation in different shapes. Vegetation can also constitute an element that can create acoustic barriers to means of transport, realizing an adequate separation between places of quick cross and spaces for break and free time. The separation from the car traffic sounds can be also carried out with the creation of other kinds of filters such as cycling lines that work as a place between the space for breaks - with slow pace - and that of car movements, necessarily quicker.

13. The possibility of perceiving naturally occurring smells - e.g. wood, grass, sea - provides a feeling of happiness. Beyond the sound and visual perceptions, the ones of smell also are important for urban happiness. The smell of nature, both vegetal and floreal, has an important function in emotivity. Furthermore, the use of natural material for the realization of urban equipment and furniture contributes to the solicitation of both smell perceptions and well-being.

14. The possibility of having direct contact with natural materials, preferably local, used in the design of the space gives a sense of well-being. The use of natural material for urban furniture, equipment and paving offer the possibility to create diverse kinds of perceptions in people who use it. When these are local, they have the double effect of contributing to the maintenance of place identity, favouring the maintenance and management of the place as well.

15. The possibility of doing actions - such as walking, watching, etc.. - with a moderate or slow pace promotes opportunities to take breaks in the space. The pace imposed by contemporary society is getting to be more and more quick. Many actions are carried out simultaneously and the use of new technologies also favour this behaviour. The velocity can be reduced with the presence of suitable break spaces and places for the purpose of both natural and artistic element enjoyment.

16. The feeling of being able to contribute to the life of that place increases the sense of belonging. There are many activities that allow to vitalize the place and people mutually, creating a perception of happiness and well-being in people who perform the activity as well as in those who observe it. These include the creation of shadows by people using artificial light reflected on a wall; the possibility to create little green spaces; the making of games through water paving; drawings on walls and panels suitably erected for this function and so on.

17. The consideration of the place symbolic of the neighbourhood improves the perception of its identity. The place becomes symbolic when people for different reasons make it their own, achieving a sense of belonging. The presence of elements of tangible and intangible charecteristics strongly contributes to that process of recognizability. In this way, the place identity is powered and its perception by people is enhanced.

18. The educational function in a place - e.g. clearly displayed information about the history of the place - increases its intrinsic value. The educational function in a place can be exercised in different ways. The attention to the care of the environment is one of the more relevant modalities. One of the examples include the realization of little green spaces with didactic function that can apprehend the productive life cycle of products as well as the importance for the environment; the realization of water mirrors that comprehend the cycle of the hydric resource, etc. Every place can suggest, with its uniqueness, a different example, which can include respect for particular categories of people, such as the elderly, children, the handicapped, etc. 
19. The possibility of using the space in different seasons and weather conditions improves its liveability and increases willingness to contribute to its good state of maintenance. A place should be suitable for all seasons, guaranteeing suitable maintenance in the less lit and low-temperature months. The presence of light structures for breaks and free time also in continuity with other structures that are external of the public space will contribute to its use and the maintenance throughout the year.

20. The possibility of using new technology to increase the knowledge about its intangible values and history can offer a more profound experience of the place. The new technologies for Internet constitute adding value to support the knowledge about a place and its use. The presence of wireless, multimedia totem and q-codes constitute elements that can support the knowledge aspect of the place from different perspectives. Furthermore, these can constitute reason of major use and socialization and success.

\section{ACHIEVING URBAN HAPPINESS}

In the sixth phase, a check on the degree of happiness is carried out. This is obtained through the study of the map of analysis by identifying both intrinsic and extrinsic factors that are capable of determining urban happiness. The aim is that of obtaining a map of the "waiting areas" where the design hypothesis can be concentrated. The intrinsic factors concern the perceptions, tradition and culture. Extrinsic factors concern the architecture, facility and urban furniture.

The areas defined as "waiting areas" concern those areas where there is a minor presence of those factors and which are underused with respect to the place in general. These areas could be represented by physical empty spaces or perceived empty spaces (e.g. a non-utilized square, an area destroyed following an environmental disaster).

The "waiting areas" are marginal with respect to the place or central, due to the fact that their position with respect to the area of study is not emblematic of its own success. The areas can also be constituted by the whole study place.

The seventh phase consists in the check of satisfaction of the 20 principles of urban happiness of the Charter. The check is carried out through the overlapping between the map of the waiting areas and the Charter of principles. The product of this phase will be represented by a mosaic of principles to be implemented.

The 20 Charter principles are considered as guidelines, namely actions and factors, which may determine the happiness of people who live in those specific places. During this phase, the 20 principles are hypothesized as having the potential to improve the waiting areas which have been identified - from the urban happiness point of view. The principles that are assessed as being suitable for these areas will be further specified in order to be contextualized appropriately.

In the eighth phase, project interventions for the realization of the principles are identified. The insertion of these project interventions in the waiting areas is carried out together with a check of consistency with spaces and urban furniture and equipment already present. In this way, a map of urban happiness design is obtained.

The ninth phase concerns the check of the design ideas with the users of the place through two typologies of questionnaires: the questionnaire on site to be administered to the users of places and the research on the web sites with the user requests. A mosaic of degree of pleasure on the design ideas is obtained.

The design hypothesis will be verified with demands selected by the person who carried out the study, which will be ad hoc with respect both to the place and the results of the eighth 
phase. Answers to the questionnaires administered on site will be overlapped with those carried out by questionnaires or web forum concerning booking of tourist services (e.g. booking or trip advisor). These questionnaires constitute the participative part of the project, and also the possibility of comprehension of the place in a wider manner. A further possibility, in the case of ad hoc created tool, will be the realization of blogs or other social network tools to support this and other phases of the project.

The tenth phase consists in the transformation of the project interventions in the design of the spaces. This will be carried out through two operations: the overlapping of the results of the previous phases and the identification of the use of the traces - urban, cultural, etc. already present in the place. The final result will be the Happy place design map.

The last design phase is the most difficult. The design of the new spaces to be harmonized with the existing ones is an important factor above all when the final objective is constituted by the urban happiness achievement, a concept that is both hardly reachable and in a certain way subjective.

The existing traces to which not only the urban ones, but also the cultural ones connect belong to memories, perceptions and other tangible and intangible factors. A detailed analysis will provide more suitable information in order to facilitate the emergence of the existing characteristics and peculiarities and connect the project of new parts.

\section{INTERACTIVE NARRATIVE MOSAICS}

The method can be supported by a computer science tool for smart phones or multimedia tablets. That tool can support during the phase of collection of information and frequency of actions, as well as during the administration and collection of questionnaires. The final product will be constituted by interactive mosaics capable to visualize places and factors that contribute to urban happiness. The software could be connected to q-codes posed on site by which download further information about the site and itineraries and places derived by the maps which are carried out can be obtained. The main users to whom the computer science tool is devoted include visitors, tourists, technicians and administrators who are interested in more liveable and sustainable places.

The software, designed in open source, can be downloaded by a web site and customized to different needs.

In the first phase, that of the identification of the area, the software allows to visualize and delimit the place. In this way, in the next windows the selected parts of the area can be visualized. A zoom function allows to scale the area, depending on the necessity of use.

In the second phase, concerning the identification of the activities, perceptions and contributing elements, the software has the function to import the collected information and to schematize on the map the movements of people, urban furniture and equipment and the activities carried out, and calculate the percentage values of these. Furthermore, the visualization of elements and movements is supported by images and video.

In the third phase concerning questionnaires, the software imports both questions administered during the sight inspections and answers that are received. The results of these answers, those relived by blogs and visitors suggestions - identified in the web sites - are reported. The software will visualize the percentage of answers given allowing to comprehend on the map the factors of major interest concerning urban happiness, which emerge from different types of users.

In the fourth phase, the traditional analysis of the places in object is imported and visualized in multimedia with pictures, both new and historical. This can be supported by news 
available on the web, which is devoted to the knowledge of both the current state of fact and history of the object area.

In the fifth phase, the software, while visualizing the transparency of all the collected and imported elements, allows to achieve narrative interactive mosaics that represent in a fluid and dynamic way the urban happiness factors of that place. The mosaics will visualize the elements and movements and make perceived sounds, rhythms and times of a space.

In the sixth phase, the test of the degree of happiness with the identification of the waiting areas is carried out with the graphic interactive representation where those areas and relative criticalities clearly emerge.

In the seventh phase, the principles of urban happiness, which are imported before the beginning of the first phase actions, which emerge as those of major interest for the waiting areas will be visualized on the mentioned areas.

In the eighth phase, in which the evidenced principles are transformed in project interventions, the project visualizes the elements and activities to be carried out in dynamic form.

In the ninth phase, the functions of the software are the same as those used for the fourth phase, and are referred to the possible ideas for urban happiness design.

Finally, in the last phase, the interactive narrative mosaics are transformed in informative and visualize sketches, design references and drawings, which detail the project in different modalities.

\section{OBSERVATION}

Studies on the intangible aspects that are connected to the city are many and involve many disciplines. To afford them in a scientific way is a continuous challenge and open to risks of subjectivity of interpretation. The method which is presented in this article is an evolution of the PlaceMaker method, which was devoted to the identification of elements, which constitutes the place identity and intervention for its enhancements. Identity of places, in its elusiveness, has constituted by very tangible elements such as the architecture of buildings, the urban morphology, etc. In line with this concept, urban happiness can be - only at the first stage of analysis - considered to be influenced by perceptions. In addition in this case, perceptions and intangible aspects are strongly connected to architectures, public spaces and natural environment.

The experiments that were carried out concern public spaces that are well known and successful, in order to comprehend reasons, movements and behaviours of people, physical elements that contribute to urban happiness. This is carried out through different kinds of surveys, among these being the survey realized using ad hoc schedules.

These, although used in different cases and in general considered suitable, can be further improved in order to comprehend data concerning movements of people, which are hardly predictable before the direct observation, different for any place and part of it.

Another focal point is the identification of the intrinsic and extrinsic elements that contribute to urban happiness. Indeed, those elements are in strong relation with each other and consequently the identification of waiting areas is complex. Nevertheless, here, the parts of interest for the design are concentrated.

Another key aspect is the correct integration between the answers to the questionnaires both of analysis and design - administered on site and collected from internet web sites. The typologies of questions, answers and people who participate in these could be very different making it difficult to have a univocal result.

Again, it is important to take into account that design hypotheses that are reached following the method are only some of the possible solutions. From Happy place mapping many different design ideas can be derived. 
Finally, the computer science tool, still under development, is in line with a modality of survey of places, which is more and more devoted to the use of technologies and social networks. It is fundamental that the technology difficulties that will be encountered in the realization phases do not lead to an oversimplification and banalization of results both of analysis and design.

\section{CONCLUSION}

The article has presented the Happy place mapping, carried out in the framework of CNR research projects.

Nowadays, more attention is paid to the topic of urban happiness but often in a theoretical sense or from an observational point of view.

Happy place mapping aims to identify urban happiness and the factors that make places happy from the users' point of view.

The method consists of surveys, observations and questionnaires. The method is supported by a software that is illustrated in the article and is still under development.

A series of case studies have been carried out on squares, pedestrian and semi-pedestrian thoroughfares, urban parks and waterfronts, and cultural districts, which are particularly representative of the city of belonging. Regarding waterfronts, these include: Hankou River in Wuhan, Lungomare Caracciolo in Naples, Bordeaux Waterfront in Bordeaux and The Bund in Shanghai. Examples of cultural districts include: 798 Art District in Beijing, Nanluoguxiang in Beijing, and Museums Quartier in Vienna. Concerning parks, the case studies include: Millenium Park in Chicago, Citygarden in Saint Louis (Missouri), and Promenade du Paillon in Nice. Regarding thoroughfares, the Ramblas in Barcelona and the Graben in Vienna were researched. Finally, the Stadtlounge in St Gallen, the Place des Voges in Paris, the Piazza del Campo in Siena and Piazza Trevi in Rome are the squares.

The results of the pilot case studies enabled the creation of the Charter of Happiness of public spaces with 20 principles which is part of the method. The 20 principles aim to provide a checklist which the project has to comply with in order to enhance the happiness of the place in question, making sure, however, that place happiness is sustainable and is not used for the sole purpose of rapid consumption of cultural resources. The principles should not be considered static, but dynamic, in keeping with the increasingly rapid rates of change in a place, which leads to a continually expanding concept of happiness. The method, the Charter and the software are meant to be flexible tools for academics, practitioners and administrators to guide the creation or enhancement of happy and sustainable places.

\section{REFERENCES}

[1] Carmona, M., Heath, T., Oc, T. \& Tiesdell, S., Public Places-Urban Spaces, Architectural Press: Oxford, 2010.

[2] Lynch, K., The Image of the City, Mit Press:Cambridge, 1960.

[3] Jacobs, J., The Death and Life of Great American Cities, New York: Random House, 1961.

[4] Appleyard, D., Livable Streets, University of California Press: Berkeley, 1981.

[5] Rose, G., Place and identity: a sense of place, In A Place in the World? Place, Cultures and Globalization, eds. D. Massey \& P. Jess, Oxford: Open University/Oxford University Press, 1995.

[6] Knox, P.L., Styles, symbolism and settings: the built environment and imperatives of urbanised capitalism. Architecture et Comportment, 2, pp. 107-122, 1984.

[7] Relph, E., Place and Placelessness, London: Pion, 1976. 
[8] Madanipour, A., Public and Private Spaces of the City, Routledge: London, 2003.

[9] Montgomery, J., Making a city: urbanity, vitality and urban design. Journal of Urban Design, 3, pp. 93-116, 1998. http://dx.doi.org/10.1080/13574809808724418

[10] Porteous, J.D., Environmental and Behavior: Planning and Everyday Urban Life, Reading, Massachusetts: Addison-Wesley, 1977.

[11] Project for Public Spaces, How to Turn a Place Around: a Handbook for Creating Successful Public Spaces, Project for Public Places: New York City, NY, 2001.

[12] Whyte, W.H., The Social Life of Small Public Space, Conservation Foundation: Washington DC, 1980.

[13] Sepe, M., Planning and Place in the City, Mapping Place Identity, Routlege: London-New York, 2013.

[14] Sepe, M., Preserving, reconstructing and enhancing the place identity: identifying principles of urban sustainability with placemaker method. International Journal of Sustainable Development and Planning, 9(2), 2014. http://dx.doi.org/10.2495/SDP-V9-N2-277-300

[15] Evans, B., McDonald, F. \& Rudlin, D., Urban Identity. Learning from Place, Routledge, Londonn: New York, 2011.

[16] Friedmann, J., Place and place-making in cities: a global perspective. Planning Theory \& Practice, 11(2). pp. 149-165, 2010. http://dx.doi.org/10.1080/14649351003759573

[17] Gehl, J., Cities For People, Island Press: Washington, 2010.

[18] Hauptmann, D. (ed) Cities in Transition, Publishers Rotterdam: Rotterdam, 2001.

[19] Lefebvre, H., The Production of Space, Basil Blackwell: London, 1991.

[20] Zelinka, A. \& Brennan, D., Safescape, Creating Safer, More Livable Communities Though Planning and Design, Planner Press APA: Chicago, 2001.

[21] Florida, R., Mellander, C. \& Rentfrow, P.J., The happiness of Cities. Regional Studies, 47, pp. 613-627, 2013. http://dx.doi.org/10.1080/00343404.2011.589830

[22] Burns, G.W., Naturally happy, naturally healthy: the role of natural environment in well-being. In eds. F.A. Huppert, N. Baylis \& B. Keverne, The Science of Well-Being, Oxford University Press: New York, 2005.

[23] Taylor, A.F., Kuo, F.E. \& Sullivan, W.C., Growing up in the inner city: Green spaces as places to grow. Environmental Behavior, 30(1), pp. 3-27, 1998. http://dx.doi.org/10.1177/0013916598301001

[24] Zidansek, A., Sustainable development and happiness in nations. Energy, 32, pp. 891-897, 2007. http://dx.doi.org/10.1016/j.energy.2006.09.016

[25] Montgomery, C., Happy City, Penguin: London, 2013.

[26] Sepe, M., Improving sustainable enhancement of cultural heritage: smart placemaking for experiential paths in pompeii. International Journal of Sustainable Development and Planning, 10(5), pp. 713-733, 2015. http://dx.doi.org/10.2495/SDP-V10-N5-713-733 